\title{
A Sensible Reappraisal of Lifestyle Modifications to Treat Hypertension
}

\author{
${ }^{1}$ Aashish Contractor, ${ }^{2}$ Abraham Samuel Babu
}

\begin{abstract}
The prevalence of hypertension worldwide is rapidly increasing and is projected to cross 1.5 billion adults by 2025 . Reduction in hypertension will provide the largest benefit for premature cardiovascular disease mortality. Lifestyle modification, which primarily includes an increase in physical activity and alterations in diet can contribute greatly to both, prevention and management of hypertension. However, in terms of specific recommendations for these lifestyle interventions, there is still a need for greater evidence from randomized controlled trials. This article reviews some of the new data in the area of lifestyle modification, for the control and management of hypertension. Regular aerobic exercise, along with dynamic resistance training has shown to have a beneficial effect in the management of hypertension. Besides structured exercise, an increase in daily physical activity has proven benefits. An increase in cardiorespiratory fitness, has shown to have a positive impact on both hypertension, and reducing cardiovascular disease morbidity and mortality. Current dietary guidelines for the management of hypertension, included a reduction in daily sodium intake and processed foods. In addition, smoking cessation, control of weight and limitation of alcohol intake contribute to a healthy lifestyle for hypertension management.
\end{abstract}

Keywords: Diet, Exercise, Hypertension, Lifestyle, Physical activity.

How to cite this article: Contractor A, Babu AS. A Sensible Reappraisal of Lifestyle Modifications to Treat Hypertension. Hypertens J 2015;1(2):68-72.

Source of support: Nil

Conflict of interest: None

\section{INTRODUCTION}

The alarming rise in the prevalence of cardiovascular disease (CVD) has prompted the need for various interventions to help curb the increase in morbidity and

\footnotetext{
${ }^{1}$ Head, ${ }^{2}$ Assistant Professor

${ }^{1}$ Department of Rehabilitation and Sports Medicine, Sir HN Reliance Foundation Hospital, Mumbai, Maharashtra, India

${ }^{2}$ Department of Physiotherapy, School of Allied Health Sciences, Manipal University, Manipal, Karnataka, India

Corresponding Author: Aashish Contractor, Head, Department of Rehabilitation and Sports Medicine, Sir HN Reliance Foundation Hospital, Mumbai-400004, Maharashtra India, e-mail: ascontractor@gmail.com
}

mortality from CVD. Hypertension (HT) has long been recognized as a major risk factor for CVD. The estimated total number of adults with hypertension worldwide in the year 2000 was 972 million; 333 million (329-336 million) in economically developed countries and 639 million (625-654 million) in economically developing countries. ${ }^{1}$ The number of adults with hypertension in 2025 is predicted to increase by about $60 \%$ to a total of 1.56 billion (1.54-1.58 billion). In India, the prevalence of HT has been rising, along with the burden of CVD. The prevalence of HT has risen over the past decades from 5 to between 20 and $40 \%$ in urban areas and 12 to $17 \%$ in rural areas. ${ }^{2,3}$ Recently, it has been seen that a reduction in HT prevalence provided the largest benefit for premature CVD-specific mortality. ${ }^{4}$ Prevention and control of HT should, therefore, be a worldwide health priority.

\section{Lifestyle Modifications to Treat Hypertension}

The use of non-pharmacological interventions for the prevention and control of HT have received attention as a crucial component by various global organizations. ${ }^{5,6}$ Adoption of healthy lifestyles is important for the management of HT. Lifestyle modifications reduce $\mathrm{BP}$, prevent or delay the incidence of $\mathrm{HT}$, enhance antihypertensive drug efficacy, and decrease cardiovascular risk. ${ }^{7}$

It is clear that there is a great need to promote nonpharmacological interventions in order to establish control and management of HT and to prevent mortality and secondary comorbidities. The following sections will briefly review how various lifestyle interventions (i.e. exercise, cardiorespiratory fitness, physical activity and diet) work towards controlling HT.

\section{Exercise and Hypertension}

Exercise has been found to have numerous cardiovascular benefits and has been the mainstay of interventions for the prevention and control of various risk factors for CVD $^{8,9}$ (Table 1).

Based on evidence from previous trials, various organizations put forward exercise training guidelines specifically targeting HT. Recently, Pescatello et al summarized these recommendations given by the American Heart Association/American College of 
Table 1: Effects of exercise training on

various cardiovascular risk factors 8,9

\begin{tabular}{ll}
\hline Cardiovascular risk factor & Effects with exercise training \\
\hline Autonomic function & $\begin{array}{l}\text { Improves heart rate variability } \\
\text { and heart rate recovery } \\
\text { Reduces pro-inflammatory } \\
\text { markers (hSCRP) } \\
\text { Inflammation }\end{array}$ \\
Lipids & $\begin{array}{l}\text { Reduction in total cholesterol, } \\
\text { triglycerides and LDL } \\
\text { increase in HDL } \\
\text { Reduces BMI, percentage } \\
\text { Obesity }\end{array}$ \\
fat and improves metabolic \\
syndrome \\
Improves blood sugar control \\
in diabetics \\
Quality of life
\end{tabular}

Cardiology, Joint National Commission (JNC)-7 and 8, American College of Sports Medicine, European Society of Hypertension/European Society of Cardiology and the Canadian Hypertension Education Program. ${ }^{10}$ These various statements have reported blood pressure reductions with exercise training in the ranges of 1 to $9 \mathrm{~mm} \mathrm{Hg}$.

Most exercise programs have focused on aerobic training with the following prescription:

- Frequency: 3 to 7 days/week

- Intensity: Moderate

- Type: Aerobic

- Time: 30 to 60 minutes per session

\section{Resistance Training}

In addition to aerobic training, resistance training has also been used in the management of HT. A meta-analysis by Cornelissen et al found that SBP and DBP reduced by 3.5 and $3.2 \mathrm{~mm} \mathrm{Hg}$ respectively; irrespective of the type of resistance training (i.e. dynamic or isometric resistance exercise). ${ }^{11}$ This showed that resistance training did in fact reduce blood pressure and was contrary to what was thought earlier.

The same group also conducted a systematic review and meta-analysis of randomized controlled trials to compare the effects of endurance training, dynamic resistance training, isometric resistance training, or combined endurance and resistance training on the magnitude of change in SBP and DBP in subclinical populations. ${ }^{12}$ Their results demonstrated that endurance training, dynamic resistance training, combined training, and isometric resistance training significantly reduced DBP and all except combined training reduce SBP. The interesting finding was that isometric resistance also reduced BP significantly. In the past, this type of resistance training was avoided, due to the fear that it led to an exaggerated BP response. ${ }^{12}$ However, at the present time there is not sufficient data to recommend isometric resistance training for patients with HT. Their analysis also suggested that in those with HT, endurance training might be superior to dynamic resistance training or combined training. Further analysis showed that exercise programs shorter than 6 months induced larger reductions in blood pressure when compared with programs of longer duration. This is due to decreasing adherence in the programs of longer durations.

At present, it would be prudent to advise dynamic resistance training 2 to 3 days of the week as an adjunct to aerobic training.

In addition to the younger age groups, the role of exercise training should be greatly emphasized especially in the elderly. Hypertension has been seen to progress with aging. ${ }^{13}$ This is due to the multiple effects aging has on the body. These include, an increase in proinflammatory markers (TNF $\alpha$, IL-6) which in turn cause endothelial dysfunction resulting in arterial stiffening and HT. Exercise training has shown to improve all these factors which helps in controlling HT and other risk factors associated with aging. ${ }^{14,15}$

\section{High Intensity Interval Training}

In addition to aerobic and resistance training, recently, high intensity interval training (HIIT) has gained a prominent place in the prevention and control of HT. High intensity interval training is an exercise intervention which consists of several brief bouts (typically 15 seconds to 4 minutes) of high-intensity exercise (typically $>85 \%$ of maximum heart rate or aerobic capacity) separated by recovery periods of lower intensity aerobic exercise or rest. ${ }^{16}$ Studies have shown that similar results have been obtained with HIIT. ${ }^{17}$ However, it is important to keep in mind that the time spent exercising is for a shorter duration when compared to aerobic and resistance training. As an extension to HIIT, running has been found to have a reduction in all-cause and CVD mortality by 30 and $45 \%$, along with an improved survival by 3 and 4.1 years, respectively. ${ }^{18}$ However, prescribing such high intensity exercise requires careful consideration and proper evaluations by exercise trained professionals (e.g. exercise physiologist or physical therapist) prior to initiating such programs.

\section{Cardiorespiratory Fitness and Hypertension}

Cardiorespiratory fitness has a role to play in the prevention and management of HT. The recently published results from the Henry Ford Project found that individuals who could achieve $\geq 12$ METs had a $20 \%$ lower risk of 
incident HT compared to participants achieving $<6$ METs (HR: 0.80; 95\% CI: 0.72-0.89). ${ }^{19}$ What is interesting is that this is not influenced by age, sex, ethnicity, obesity, resting blood pressure and diabetes. Similar findings were also seen among the elderly. ${ }^{20}$ The genetics fitness obesity and risk of hypertension (HYPGENE) study found that cardiorespiratory fitness was the strongest predictor for $\mathrm{HT}$ with each $1 \mathrm{MET}$ increase being associated with a risk reduction for HT by $19 \%$ (95\% CI, $12-24 \%) .{ }^{21}$ Considering the benefits of exercise and the significant risk benefit with improved cardiorespiratory fitness, there is a great emphasis to improve cardiorespiratory fitness through any form of exercise training.

\section{Physical Activity and Hypertension}

An increase in physical activity (PA) has received great emphasis for the prevention of various CVD risk factors in the recent past. Studies have shown that physical inactivity or sitting time increased the risk of mortality with hazard ratios of 1.02 (95\% CI, 0.95-1.09), 1.15 (1.06$1.25)$, and 1.40 (1.27-1.55) for sitting times ranging from 4 to $<8$ hours/day, 8 to $<11$ hours/day, and $>11$ hours/day) when compared to those who sat $<4$ hours/day. ${ }^{22}$ Physical activity works through numerous mechanisms similar to exercise training that help to improve the control of HT (Fig. 1). ${ }^{23}$

It is, therefore, no surprise that PA promotion using a pedometer has found to decrease blood pressure by $3.8 / 0.3 \mathrm{~mm} \mathrm{Hg}$. A recent meta-analysis of all randomized controlled trials found when compared to usual care, PA promotion reduced SBP with ranges between 5 and $15 \mathrm{~mm} \mathrm{Hg}$, with no significant change in DBP. ${ }^{24}$ Similar findings were also seen across ethnicities. Despite the strong rationale for PA promotion, there continues to be limited funding available for various PA research. ${ }^{25}$

\section{Diet and Hypertension}

Diet is an important component of any lifestyle intervention. The most common diet used in HT is perhaps

Endothelial function

Insulin sensitivity

Sodium handling

Baroreflex sensitivity

Parasympathetic activity

Angiogenesis and arteriogenesis

Arterial compliance

Arterial lumen diameter

$$
\begin{aligned}
& \text { Vascular resistance } \\
& \text { Arterial stiffness } \\
& \text { Oxidative stress } \\
& \text { Inflammation } \\
& \text { Body weight } \\
& \text { Sympathetic activity } \\
& \text { Intima-media thickness } \\
& \text { Psychosocial stress }
\end{aligned}
$$

Fig. 1: Mechanisms by which physical activity prevents and controls hypertension ${ }^{23}$ the dietary approach to stop hypertension (DASH) diet. This diet is rich in fruits, vegetables, low fat or nonfat dairy and also includes whole grains, lean meats, fish and poultry and nuts and beans. In short, it is high in fiber and low to moderate in fat. This diet has been found to reduce systolic and diastolic blood pressure by $5.2 \mathrm{~mm} \mathrm{Hg}(95 \% \mathrm{CI}-7.0$ to $-3.4 ; \mathrm{p}<0.001)$ and $2.6 \mathrm{~mm} \mathrm{Hg}$ $(95 \% \mathrm{CI}-3.5$, to $-1.7 ; \mathrm{p}<0.001)$ in a recent meta-analysis. ${ }^{26}$ A Mediterranean diet supplemented with extra-virgin oil or nuts has been shown to reduce the incidence of major cardiovascular events. The diet is fairly similar to the DASH diet, but also includes a high intake of olive oil. ${ }^{27}$ A recent Cochrane review found that with moderate reduction in dietary salt intake by $\sim 4.4 \mathrm{gm} /$ day there was a mean reduction in blood pressure by $4.18 \mathrm{~mm} \mathrm{Hg}(95 \%$ CI: -5.18 to -3.18$)$ and $2.06 \mathrm{~mm} \mathrm{Hg}$ (95\% CI: -2.67 to -1.45$)$ for systolic and diastolic blood pressure, respectively. ${ }^{28}$ Most dietary guidelines advocate lowering sodium intake, and consuming no more than $2400 \mathrm{mg}$ of sodium per day. It has also been suggested that further reduction of sodium intake to $1500 \mathrm{mg}$ per day, could result in greater reduction in $\mathrm{BP}^{29}$

Several studies have shown a BP-reducing effect by potassium intake either by consumption of more fruits and vegetables, salt-substitutes and enrichment, or supplementation; and these studies suggest that it also plays a cardioprotective role. The BP-lowering benefit has been shown in both normotensive and hypertensive individuals. ${ }^{30}$ Dietary advice is crucial to the prevention and control of HT. It has been shown that with dietary advice, reduction in SBP by $2.6 \mathrm{~mm} \mathrm{Hg}(95 \%$ CI 1.31 to 3.91) and DBP by $1.4 \mathrm{~mm} \mathrm{Hg}$ (95\% CI 0.68 to 2.22) can be achieved in 3 months. ${ }^{31}$ Traditionally, salt consumption in diet has been the main subject of focus, but in recent years, there is data emerging, which indicate that added sugars, particularly fructose, may lead to an increase in $\mathrm{BP}^{32} \mathrm{~A}$ recent meta-analysis of randomized control trials of the effect of dietary sugars on BP showed that in trials, which were greater than 8 weeks in duration, the mean difference of systolic and diastolic BP, was $6.9 \mathrm{~mm} \mathrm{Hg}$, and $5.6 \mathrm{~mm} \mathrm{Hg}$, respectively. ${ }^{33}$ Industrially, processed foods are a large source of sodium in the diet, but they are usually also high in added sugars.

\section{DISCUSSION}

Hypertension is a major risk factor for CVD. At the present moment, there is substantial lack of evidence on many issues surrounding BP treatment and management, including exercise prescription..$^{10}$ Nonpharmacological interventions using exercise, physical activity and diet help in the prevention and control of HT, and should be the mainstay of lifestyle recommendations. In addition, 
for overall and cardiovascular health, those who smoke should be strongly advised to quit. For those who are overweight, weight loss of as little as $10 \mathrm{lbs}(4.5 \mathrm{~kg})$ reduces $\mathrm{BP}$ and/or prevents $\mathrm{HT}$ in a large proportion of overweight persons. ${ }^{7}$ Regular physical activity of moderate intensity, of 30 minutes or more on most days of the week, is recommended for both the prevention and management of HT. In addition, resistance training on 2 or 3 days of the week is recommended. Dietary recommendations, include reduction in sodium intake and limiting sodium intake to no more than 2,400 mg per day. Recent data also implicate an excess of sugar in the diet as a contributing factor towards HT, and the recommendation is to limit the intake of sugar and salt, especially in processed foods.

With recent advancements in technology, there is a need to study how social media and technology can be used to help control HT better. The utilization of home-based programs and physical activity promotion programs are in their infancy and need to be explored in greater detail. These can help in adherence to lifestyle modifications and can have an impact on the prevention and control of HT and indirectly on the CVD burden.

\section{REFERENCES}

1. Kearney P, Whelton M, Reynolds K, Muntner P, Whelton $\mathrm{P}$, He J. Global burden of hypertension: analysis of worldwide data. The Lancet 2005;365(9455):217-223.

2. Gupta R. Trends in hypertension epidemiology in India. J Hum Hypertens 2004;18(2):73-78.

3. Srinath Reddy K, Shah B, Varghese C, Ramadoss A. Responding to the threat of chronic diseases in India. The Lancet 2005;366(9498):1744-1749.

4. Roth G, Nguyen G, Forouzanfar M, Mokdad A, Naghavi M, Murray C. Estimates of global and regional premature cardiovascular mortality in 2025. Circulation 2015;132(13): 1270-1282.

5. Thomas R, King M, Lui K, Oldridge N, Pina I, Spertus J. AACVPR/ACCF/AHA 2010 Update: Performance Measures on Cardiac Rehabilitation for Referral to Cardiac Rehabilitation/Secondary Prevention Services: A Report of the American Association of Cardiovascular and Pulmonary Rehabilitation and the American College of Cardiology Foundation/American Heart Association Task Force on Performance Measures (Writing Committee to Develop Clinical Performance Measures for Cardiac Rehabilitation). Circulation. 2010;122(13):1342-1350.

6. Piepoli M, Corra U, Adamopoulos S, Benzer W, BjarnasonWehrens B, Cupples $M$, et al. Secondary prevention in the clinical management of patients with cardiovascular diseases. Core components, standards and outcome measures for referral and delivery: A Policy Statement from the Cardiac Rehabilitation Section of the European Association for Cardiovascular Prevention and Rehabilitation. Endorsed by the Committee for Practice Guidelines of the European Society of Cardiology. European J Prevent Cardiol 2012;21(6):664-681.
7. Chobanian AV, Bakris GL, Black HR, Cushman WC, Green LA, Izzo JL Jr, et al. Seventh report of the Joint National Committee on prevention, detection, evaluation, and treatment of high blood pressure. Hypertension 2003 Dec;42(6): 1206-1252.

8. Swift DL, Lavie CJ, Johannsen NM, Arena R, Earnest CP, O'Keefe JH, et al. Physical activity, cardiorespiratory fitness, and exercise training in primary and secondary coronary prevention. Circ J 2013;77(2):281-292.

9. Lavie C, Arena R, Swift D, Johannsen N, Sui X, Lee D, et al. Exercise and the cardiovascular system. Circulation Research 2015;117(2):207-219.

10. Pescatello LS, MacDonald HV, Ash GI, Lamberti LM, Farquhar WB, Arena R, Johnson BT. Assessing the existing professional exercise recommendations for hypertension: a review and recommendations for future research priorities. Mayo Clin Proc 2015 Jun;90(6):801-812.

11. Cornelissen V, Fagard R, Coeckelberghs E, Vanhees L. Impact of resistance training on blood pressure and other cardiovascular risk factors: a meta-analysis of randomized, controlled trials. Hypertension 2011;58(5):950-958.

12. Cornelissen V, Smart N. Exercise training for blood pressure: a systematic review and meta-analysis. J Am Heart Assoc 2012;2(1):e004473.

13. Sun Z. Aging, arterial stiffness, and hypertension. Hypertension 2015;65(2):252-256.

14. Rich MW. Secondary prevention of cardiovascular disease in older adults. Prog Cardiovasc Dis 2014 Sep-Oct;57(2):168-175.

15. Fleg J, Forman D, Berra K, Bittner V, Blumenthal J, Chen M, et al. Secondary prevention of atherosclerotic cardiovascular disease in older adults: a scientific statement from the American Heart Association. Circulation 2013;128(22): 2422-2446.

16. Gibala M, Little J, MacDonald M, Hawley J. Physiological adaptations to low-volume, high-intensity interval training in health and disease. J Physiol 2012;590(5):1077-1084.

17. Nybo L, Sundstrup E, Jakobsen MD, Mohr M, Hornstrup T, Simonsen $\mathrm{L}$, et al. High-intensity training versus traditional exercise interventions for promoting health. Med Sci Sports Exerc 2010 Oct;42(10):1951-1958.

18. Lavie C, Lee D, Sui X, Arena R, O'Keefe J, Church T, et al. Effects of running on chronic diseases and cardiovascular and all-cause mortality. Mayo Clin Proc 2015 Nov;90(11): 1541-1552.

19. Juraschek $S$, Blaha M, Whelton $S$, Blumenthal R, Jones $S$, Keteyian $S$, et al. Physical fitness and hypertension in a population at risk for cardiovascular disease: the Henry Ford Exercise Testing (FIT) project. J Am Heart Assoc 2014; 3(6):e001268.

20. Faselis C, Doumas M, Pittaras A, Narayan P, Myers J, Tsimploulis A, et al. Exercise capacity and all-cause mortality in male veterans with hypertension aged $\geq 70$ years. Hypertension 2014;64(1):30-35.

21. Rankinen T, Church TS, Rice T, Bouchard C, Blair SN. Cardiorespiratory fitness, BMI, and risk of hypertension: the HYPGENE study. Med Sci Sports Exerc 2007 Oct;39(10): 1687-1692.

22. van der Ploeg H. Sitting time and all-cause mortality risk in 222,497 Australian adults. Arch Intern Med 2012;172(6):494.

23. Diaz K, Shimbo D. Physical activity and the prevention of hypertension. Curr Hypertens Rep 2013;15(6):659-668. 
24. Semlitsch T, Jeitler K, Hemkens L, Horvath K, Nagele E, Schuermann $\mathrm{C}$, et al. Increasing physical activity for the treatment of hypertension: a systematic review and metaanalysis. Sports Med 2013;43(10):1009-1023.

25. Fernhall B, Borghi-Silva A, Babu A. The future of physical activity research: funding, opportunities and challenges. Progress in Cardiovascular Diseases 2015;57(4):299-305.

26. Siervo M, Lara J, Chowdhury S, Ashor A, Oggioni C, Mathers J. Effects of the dietary approach to stop hypertension diet on cardiovascular risk factors: a systematic review and meta-analysis. Br J Nutrition 2015;113(1): $1-15$.

27. Estruch R, Ros E, Salas-Salvadó J, Covas MI, Corella D, Arós F, et al. Primary prevention of cardiovascular disease with a Mediterranean diet. N Engl J Med 2013;368(14):1279-1290.

28. He F, Li J, MacGregor G. Effect of longer term modest salt reduction on blood pressure: cochrane systematic review and meta-analysis of randomised trials. BMJ 2013 Apr 3;346(3):f1325.
29. Eckel R, Jakicic J, Ard J, de Jesus J, Miller N, Hubbard V, et al. AHA/ACC guideline on lifestyle management to reduce cardiovascular risk: a report of the American College of Cardiology/American Heart Association Task Force on Practice Guidelines. Circulation 2013;129(25_suppl_2):S76-S99.

30. Aaron KJ, Sanders PW. Role of dietary salt and potassium intake in cardiovascular health and disease: a review of the evidence. Mayo Clin Proc 2013;88(9):987-995.

31. Rees K, Dyakova M, Ward K, Thorogood M, Brunner E. Dietary advice for reducing cardiovascular risk. Cochrane Database Syst Rev 2013 Mar 28;3:CD002128.

32. DiNicolantonio J, Lucan S. The wrong white crystals: not salt but sugar as aetiological in hypertension and cardiometabolic disease. Open Heart 2014 Nov 3;1(1):e000167.

33. Te Morenga L, Howatson A, Jones R, Mann J. Dietary sugars and cardiometabolic risk: systematic review and metaanalyses of randomized controlled trials of the effects on blood pressure and lipids. Am J Clin Nutrition 2014;100(1):65-79. 